\title{
Dynamics and evolution of urban patterns: the evidence of the Mobile Landscape project
}

\author{
S. Bastianoni, R. M. Pulselli, P. Romano \& F. M. Pulselli \\ Department of Chemical and Biosystems Sciences, \\ University of Siena, Italy
}

\begin{abstract}
This research is focussed on city and territory and it develops innovative approaches for urban studies. In particular, this project studies the relationships between dynamic components, the cities users, and the physical environment, such as the buildings, the containers of functions and the infrastructures. In fact this study aims to understand where, when, how intensively and how long a territorial system is used. This research develops an evolutionary approach to urban studies and concerns the development of a new method of urban monitoring, called Mobile Landscapes. The new vision of the city, conceived as a complex system, is an efficient strategy for facing the problems of the contemporary city, such as continuous growth, mobility and atmospheric pollution. The presented technique elaborates location based data from cell phones through GIS tools, to study the distribution of the urban activity in space and in time and to appraise the density of the cities' users and their movements through the territory. The case study described in this paper uses data from cell phones antennas in the metropolitan area of Pescara-Chieti, Italy, and is relative to a previous work in the city centre of Milan. In this case, a wider area, which includes both the urban and rural areas, is examined. Commuting data from peripheral coastal areas to the city of Pescara were detected and measured in working days. Results show that the concentration of activity is higher in a limited area of the coast and, especially in summer, a higher activity is recorded along the entire coast due to the presence of tourists.
\end{abstract}

Keywords: mobile phone network, cell, activity, mobility patterns, geodemography. 


\section{Introduction}

This research develops and verifies a technique of monitoring that appraises the use of territory in time and space and contributes to the understanding of the functioning of territorial systems. The results obtained have two different implications. First: they concern the functioning and behaviour of urban systems, conceived as complex systems $[1,2]$; second: they concern the management and development of the city. These aspects, both theoretical and practical, make this research important in the field of urban studies. The monitoring technique applied here was recently developed at the Department of Chemical and Biosystems Sciences of the University of Siena (Italy) in collaboration with the MIT SENSEable City Laboratory in Cambridge (USA). It develops services based on mobile telecommunications, namely Location Based Services (LBS) $[3,4]$, but instead of providing services to individual cell phone users (e.g. navigational aids/tools, emergency, interactivity with the physical environment, interactivity with other users), it tries to understand the general behaviour of the social territorial system. It studies the interactions between city users and the physical space, with their functions and infrastructures.

A previous study, developed in the central area of Milan [5], allowed this technique to be tested in a high density urban area and aided understanding of the general social behaviour in the urban context during office hours, lunch time, evenings of working and festive days, evaluating variations when particular public and sporting events occurred.

This paper outlines the results of a new case study in the metropolitan area of Pescara-Chieti (Italy). This case study is different from the other one, because of the dimension of the examined area (about $960 \mathrm{~km}^{2}$ with respect to the $400 \mathrm{~km}^{2}$ of Milan), the territorial context (urbanized areas with different concentrations, alternated with rural areas, instead of the compact and homogeneous urbanized context) and the presence of a coastal area instead of continental.

The results obtained, thanks to this study, have two different implications: the first concerns the functioning of the territorial system examined; the second concerns the efficacy and validity of the developed technique of monitoring.

Regarding the first point, the study shows the areas where the activity is located and allows one to underline some phenomena, for example the variations of distribution of activity along the coast in summer and in the other seasons. Regarding the second point, the monitoring technique and the methodology was discussed.

\section{Technique and methodology}

The monitoring technique deals with data from cell phone activity and records the number of calls for each hour. It is based on two assumptions: the first results from statistic analyses about the distribution of cell phones among people in Italy (more or less 1 cell phone per capita); the second defines a relationship between the activity of cell phones and the real presence of people in the area examined. 
The administrator of cell phones, which provided data used in this study, currently control more than $60 \%$ of the total amount of traffic (of cell phones) in the area examined. Data, collected and processed in an aggregated and anonymous form, referred to the activity of cell phones recorded during 154 days, which is equivalent to 3696 hours.

The physical component of the telephone network and in particular its structure and spatial configuration on the territorial system were also investigated. Data were collected for each cell. A cell is the physical field that was covered by the signal of each antenna (Figure 1). This study used 161 cells. In the reality each cell is assimilable to an ellipsoid; this study simplified the spatial model of the cell and associated the cell with a point, the projection of the centre of ellipsoid upon the plane (land). The spatial location of the points (cells) resulted automatically from the location of the antenna, its angular direction and its ray of coverage (distance covered by the signal). The configuration of the telephone network shows that the distribution of cells is not homogeneous and that there is a higher concentration in urban areas, in particular in the city centre of Pescara.

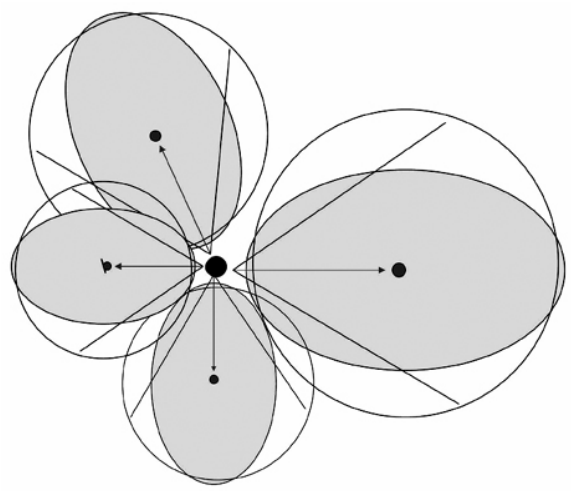

Figure 1: $\quad$ Scheme of the antenna-cells system; the central point corresponds to the antenna, while the ellipsoids show the cells with a different orientation and ray of coverage.

The analysis of this configuration reveals some phenomena: the frequent overlap of the cells in urban areas, low accuracy of data in rural areas and the different weight of the cells, in terms of intensity of cell phone activity, according to the value of the concentration of cells (number of cells per area). Moreover, in a few cases, we edited the location of points (cells) on the basis of urban density. In fact the power of the antenna is responsible for both dimension and carrying capacity of the cell (number of calls). Consequently we delivered more weight to the carrying capacity of the cell rather than to the dimension of the cell itself in urban areas with high density. Furthermore, even if the understanding of the concentration of activity of cell phones is usually less accurate in rural areas, there are some cases in which the quality and detail of the 
data should be more significant: for example the presence of the main connections between the towns.

Finally, when we found an equal intensity of activity recorded in different cells, we gave a higher weight (in terms of intensity of activity) to those cells with dimensions smaller than the others. In these cases we changed the original data on the basis of an index of cell concentration (number of cells within a given area).

After fixing the geometry of the telephone network, we could check data on the activity of cell phones and found that some cells behave anomalously, such as those with a very low activity among many other cells with a very high activity.

Then we processed the data and finally plotted them onto a sequence of maps, which represent the intensity of urban activities and their evolution through space and time. These maps were elaborated through spatial analyst tools, which allow delivery of a value to unknown points on the basis of the intensity of activity, the coordinates of known points (cells) and the effective distance between known and unknown points. The maps describing the intensity and distribution of cell phone activity on the territory were integrated by quantitative diagrams and interpretative sketches that enabled the understanding of the geographical phenomenon.

In the analysis of the outcomes, we started studying the total territorial system at the macro scale, and then we focussed on specific areas with the highest concentration of activity.

\section{Results and discussion}

The study of the Pescara-Chieti metropolitan area produced several outcomes; some of them contributed to the understanding of the functioning of the territorial system examined, some others confirmed predictable and known behaviours. In particular the study concerns three themes: the evaluation of trends relative to the intensity of cell phone activity (expressed in terms of the number of calls); the understanding of the structure (organization) of a metropolitan area; and the organization of a coastal area relative to the variation in seasons and to the phenomenon of the bathing season.

The outcomes highlighted a repetitive trend in most of the year, with an intense variation during weekends and in summer. The concentration of activity was higher in the day-time and lower at night, as predictable. The mean value of intensity decreases on Saturdays and Sundays. The phenomenon of city lighting (in the early morning) pointed out that the activity starts and increases at 7 a.m. and achieves a high intensity at around 10 a.m. The same phenomenon starts two hours later on Saturdays and on Sundays. A repetitive phenomenon, which happens both during weekdays and on Sundays, was a decrease of activity at 3 p.m., in relation to lunch time. At the end of the day the activity drops at 11 p.m.; this phenomenon starts two or three hours later on Fridays, Saturdays and Sundays (Figure 2). 


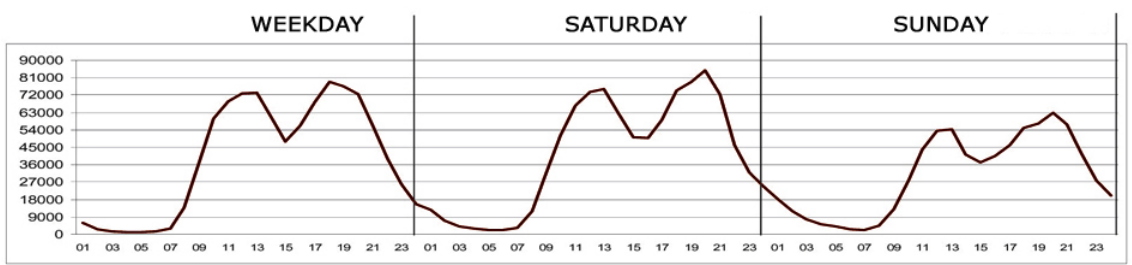

Figure 2: $\quad$ Activity diagram (number of calls).

The second step concerned the data processing and the integration of intensity with qualitative data concerning the distribution of people on the territory. The maps enabled understanding of the functioning of the whole system and highlighted the areas of the territory where the activity was concentrated; in this connection the outcome pointed out two spatial areas, one with high intensity, and the other with low intensity. The area with high intensity follows three lines, one along the coast, and the other two from the coastline (from Montesilvano and Pescara respectively) to the inland regions. In fact the outcomes highlighted a concentration of activity, equal to the $60 \%$, in this area, that mirrors the geographical system of hills, valleys and the coast. This value grows to $80 \%$ in summer.

Even considering the way in which the activity of the territorial system increases in the morning and decreases in the evening, we observed that the system is structured along the three lines (Figure 3).

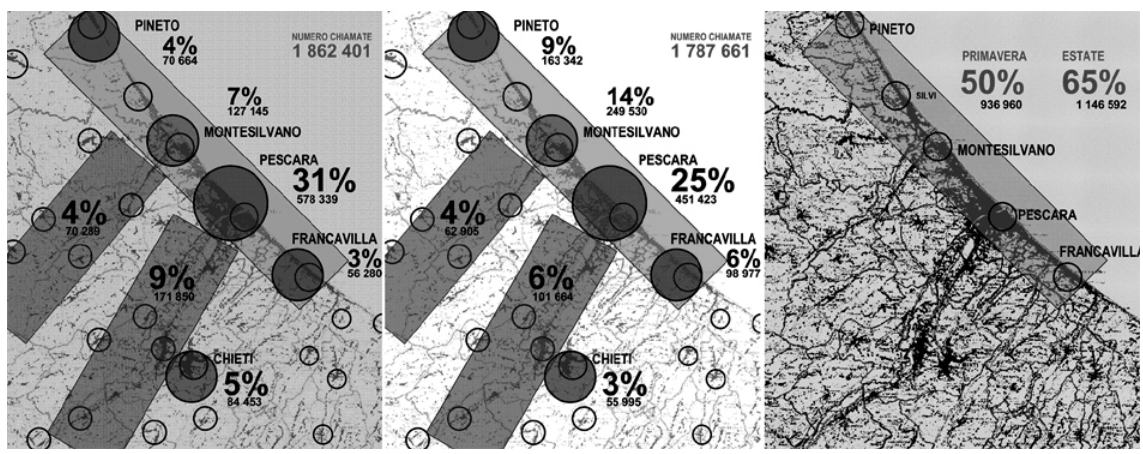

Figure 3: Distribution of activity in the high intensity areas: spring weekday (left), summer weekday (centre); percentage of activity in spring and summer along the coastline (right).

In particular the maps highlighted the presence of hotspots corresponding to the main cities in the metropolitan area such as Pescara, Pineto, Montesilvano, Francavilla on the coastline, and Chieti, Chieti Scalo, Manoppello, and the area between Cappelle sul Tavo and Città Sant'Angelo in the inland regions. The social behaviour was found to be repetitive in most of the seasons, with the exception of summer, when the activity tends to be concentrated along the coast. 
Analysing evenings, the outcomes revealed a progressive deceleration of activity, which reached a condition with lowest intensity at around 11 p.m.

In general, the areas where activity persists for a longer time and is more intensive are concentrated along the coast, in particular close to Montesilvano, Pescara and Francavilla. Summer is different. In fact the activity tends to be distributed along the entire coast from Atri to Francavilla.

The emergence of seasonal variations of the activity and the concentration of this phenomenon in the coastal area led to the choosing this area for a deeper study.

This detailed analysis focussed on an area of $200 \mathrm{~km}^{2}$ that includes a $38 \mathrm{~km}$ coastline and corresponds to a portion of about $20 \%$ of the territory under study. The outcomes show a concentration of activity in this coastal area, which is about $50 \%$ of the total in most of the seasons and about $65 \%$ in summer due to the bathing source. Looking at the distribution of activity in relation to the entire 24 hours, the outcomes highlighted similar behaviours during weekdays, Saturdays and Sundays of the different seasons, with the exception of summer. In summer the distribution of activity is similar on weekdays, Saturdays and Sundays. The highest intensity is reached during sun hours (3-6 p.m.) of the summer weekends.

Analysing the weekdays of spring, autumn and winter, the outcomes pointed out that the activity was concentrated between Pescara and Montesilvano and towards the inland, where productive and hand-crafted areas are located, along the main connections. Comparing Saturdays and Sundays with weekdays, the outcomes revealed that the activity tends to concentrate in a small area, which includes the central places of Pescara and Montesilavano, where an increase of activity is recorded. Looking at the summer period, this study revealed a

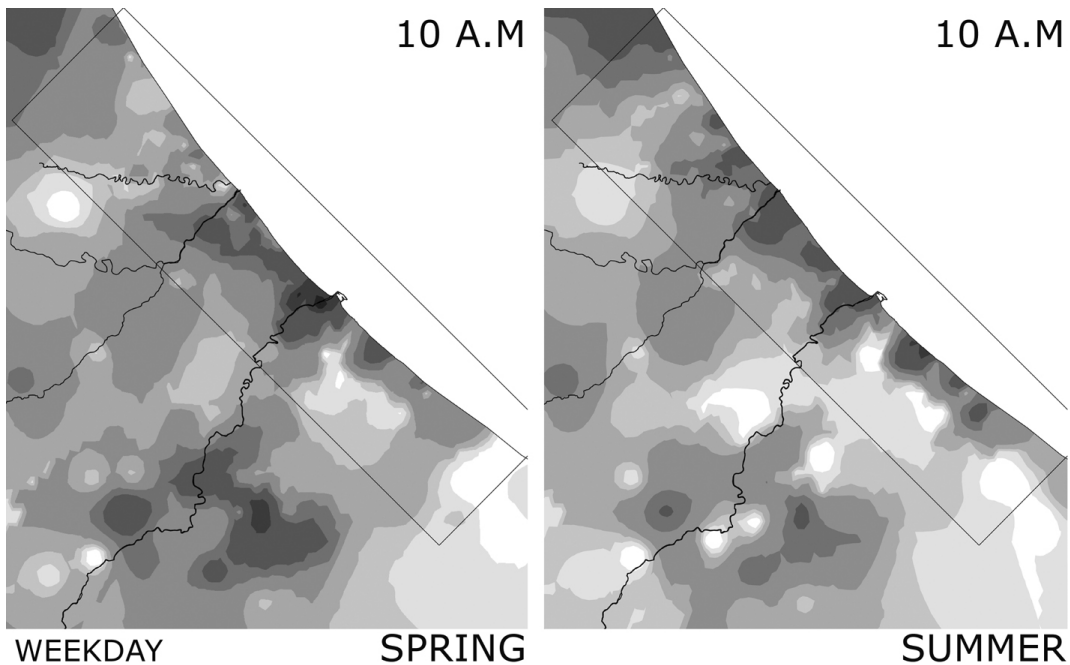

Figure 4: Distribution of activity in the territory during the morning: comparing a spring weekday (left) with a summer weekday (right). 

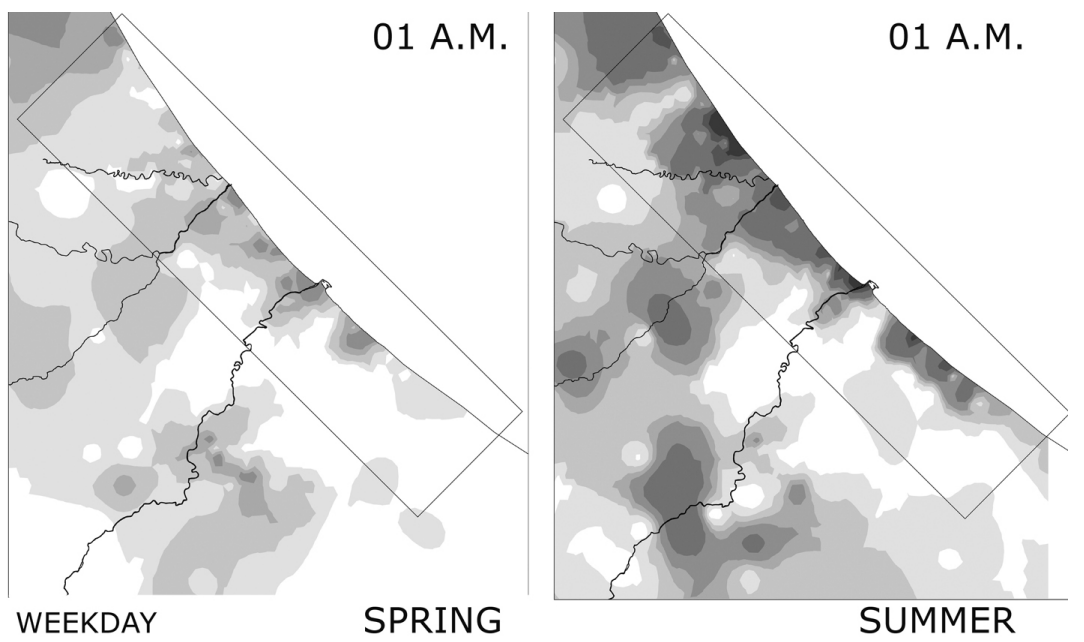

Figure 5: Distribution of activity in the territory during the night: comparing a spring weekday (left) with a summer weekday (right).
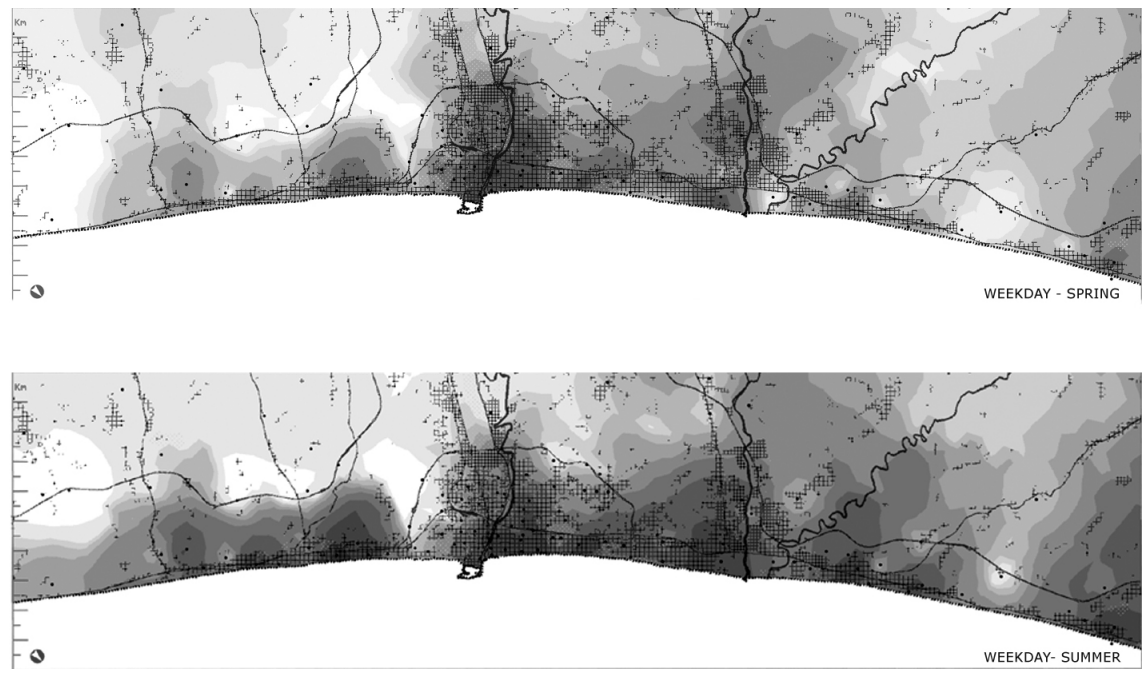

Figure 6: Distribution of activity along the coastal area; comparing spring (upper) with summer (bottom).

substantial variation of activity distribution in terms of space and time. In fact the activity tends to be concentrated along the coastline in a widespread and homogeneous way from Foro to Silvi (Figure 6). In fact, in summer, the bathing activity becomes the predominant function in the area. Comparing the summer activity, in terms of intensity, with the activity of the other seasons, the outcomes showed that some places within the city of Pescara (the area included Viale Marconi, Piazza Italia, Corso Umberto I and via Cavour), which are usually very 
busy, tend to empty while the activity in peripheral areas increases (percentage increase in respect to the spring period: $+0,8$ Francavilla, $+1,9$ Silvi, $+1,1$ Pineto). With respect to spring time the decrease of activity in the central places of Pescara was at the maximum during sun hours $(10 \mathrm{am}-6 \mathrm{pm})$; this decreases gradually during the evening, when the activity (in terms of the ratio between summer and spring) tends to increase after 10 p.m. Comparing summer with spring, Montesilvano shows the minimum increase of activity among all the urban areas; this phenomenon confirmed the urban role of Montesilvano, more similar to Pescara rather than to the other centres, which had a predominant role connected exclusively to the bathing tourism.

\section{Conclusions}

This study showed two types of outcomes: the first concerned the general understanding of the metropolitan territorial system, Pescara-Chieti; the second tested the monitoring technique.

Regarding the first theme, the variation of the activity and its distribution revealed different functional areas according to time use. For example, it showed places with an urban function, such as Pescara and Montesilvano, productive and handed-craft places, the places for entertainment and places with a touristbathing vocation. Therefore, we obtained information about the functioning and the vocations of the territory.

With respect to the second theme, the outcomes allowed us to evaluate both the monitoring technique and the methodology. This confirmed the opportunity of developing this technique in the future, especially increasing the quality of the data, increasing for example the temporal and spatial detail of data recorded by the antennas.

Future applications will concern human mobility in urban systems especially with respect to the problems of over-crowding and air pollution.

\section{References}

[1] Tiezzi E, 2006. Steps towards an evolutionary physics. WIT Press. Southampton, UK.

[2] Pulselli R M, Ratti C, Tiezzi E, 2006. City out of chaos: social patterns and organization in urban systems. International Journal of Ecodynamics 1(2) 125-134.

[3] Adams P M, Ashwell G W B, Baxter R, 2003. Location-based services: an overview of the standards. BT Technology Journal 21 34-43.

[4] Ahas R, Mark Ü, 2005. Location services: new challenges for planning and public administration? Futures 37 547-561.

[5] Ratti C, Williams S, Frenchman D, Pulselli R M, 2006. Mobile Landscapes: using location data from cell phones for urban analysis. Environment \& Planning B: Planning and Design 33(5) 727-748. 